\title{
Finding Suitable Stands for Clearcutting and Reforestation by Combining GIS Thematic Maps Expressed by Standard Scores: A Case Study in the University of Tokyo Chiba Forest
}

\author{
Takuya Hiroshima*1
}

\begin{abstract}
In this study, suitable sites for clearcutting and reforestation were found by combining GIS thematic maps expressed by standard scores in the case of the University of Tokyo Chiba Forest. The map themes were stand age over rotation age, site quality, accessibility and slope stability, and they were combined after conversion of original units into a common scale of standard scores. Then, planted stands suitable for clearcutting and reforestation were selected considering yarding feasibility. As a result, 18 sub-compartments were selected as candidate stands that had combined scores over 50 in the combined thematic map with stand sizes over 3 ha. Finally, 6 sub-compartments passed the yarding feasibility check to see if there was any obstacle along the sky line of cable logging between the two peaks in the visible area from the neighboring yard. A standard score was useful to set several thematic maps into a common scale when they were combined and to select subcompartments almost better than an average in all aspects of thematic maps. The suggested method was flexible and could contribute to a wider use of GIS in the field of forest planning.
\end{abstract}

keyword: GIS, standard score, thematic map

\section{INTRODUCTION}

Recently new systems have started such as direct payments of silvicultural subsidies in 2011 and a forest management planning system in 2012. To cope with changes in such systems, forestry officers, planners and researchers in the field of forest planning are required GIS techniques to make silviculture, harvesting and logging strategies considering integration of tending sites and construction of an efficient road network.

In this circumstances, it has become gradually common to make a comprehensive forest management plan using GIS considering a log price, a logging cost, labor requirements, etc. according to stand and terrain conditions, with optimization techniques in some cases, such as zoning of planted forests (Kawata and Matsumura, 2006; Tatsuhara, 2008; Tatsuhara and Dobashi, 2006), harvest scheduling (Lee and Minowa, 2002; Watanabe and Tatsuhara, 2013), logging cost estimation (Toyama and Tatsuhara, 2007), multiple

Corresponding author: Takuya Hiroshima

\footnotetext{
${ }^{* 1}$ The University of Tokyo Chiba Forest, Graduate School of Agricultural and Life Sciences, the University of Tokyo, Amatsu 770, Kamogawa, Chiba 299-5503, Japan

E-mail: hiroshim@uf.a.u-tokyo.ac.jp
}

forest function assessment (Wu and Minowa, 2004; Zheng and Nagumo, 1994) and profitability and yield simulation of clearcutting and thinning (Toyama et al., 2012; Yamada and Tatsuhara; 2012). The use of GIS in forest planning is not only for planted forests but also for natural and mixed forests such as landscape managements (Sano et al., 1994; 2009) and those with optimization (Sano et al., 1996; Sano and Sakamoto, 1998). Not such comprehensively but more simply, many studies have used GIS to find suitable sites for forest management such as clearcutting (Hiroshima and Nakajima, 2009), thinning (Moriya et al., 2013), logging (Umezawa et al., 2013), natural vegetation (Nakaya et al., 2014) and so on. This paper is also interested in finding harvestable and reforestable sites using GIS in the study site of the University of Tokyo Chiba Forest.

The University of Tokyo Chiba Forest had planted forests of 825 ha in area with a growing stock of about $238,000 \mathrm{~m} 3$ in 2011. The conventional forest management plan was approved for the years from 2010 to 2014, in which clearcutting and thinning were scheduled for the planted forests annually. However, the need for revising the conventional plan arose to receive the new silvicultural subsidies by the direct payment system that required the renewal of the plan in line with the new forest management planning system (The University of Tokyo Chiba Forest, 2012; Toyama et al., 2013). To make the renewal plan, there was the needs for finding clearcutting and reforestation stands for coming 5 years.

Thus, the purpose of this study is to find suitable sites 
for clearcutting and following reforestation using GIS thematic maps such as site quality, accessibility, slope stability and visibility particularly with a common scale of standard scores in the case of the University of Tokyo Chiba Forest.

\section{MATERIALS AND METHODS}

\section{Study Area}

The University of Tokyo Chiba Forest is located at the southeastern part of the Boso peninsula, Japan, between longitudes of $140^{\circ} 05^{\prime} 33^{\prime \prime}$ to $10^{\prime} 10^{\prime \prime} \mathrm{E}$ and latitudes of $35^{\circ} 08^{\prime} 25^{\prime \prime}$ to 12 '51"N. The terrain of the Chiba Forest is generally steep, e.g. a mean slope angle of planted stands was $26.4^{\circ}$, and vulnerable to land collapse. Thus cable logging was encouraged for a suitable logging system according to the terrain index (Kato, 1967) in most of the planted forests.

This area belongs to the warm temperate zone that has mean annual precipitation of $2,279 \mathrm{~mm}$ with monthly means ranging from $96.7 \mathrm{~mm}$ in December to $277.0 \mathrm{~mm}$ in September, and that has mean annual temperature of $14.2^{\circ} \mathrm{C}$ with monthly means ranging from $4.4^{\circ} \mathrm{C}$ in February to 24.2 ${ }^{\circ} \mathrm{C}$ in August according to the observations by local weather stations. A soil type is the brown forest.

In this study, targets of clearcutting and reforestation for 5 years were the planted forests. The planted forests of 825 ha in the Chiba Forest had the mean stand age of 69 years old in 2011 and were basically managed under the rotation age of 80 years old.

\section{GIS Data}

GIS data used for the following analysis were dominant tree heights and positions of Japanese cedar obtained by an airborne LiDAR (Nakajima et al., 2011), a 10-m grid resolution digital elevation model (DEM), a terrain map in a scale of 1 / 2,500 , a forest type map, a forest road map including logging yards and inventory data for each sub-compartment. The dominant tree height data consisted of 687 tree points at various stand ages from 18 to 102 years old. The DEM covered the elevation from $40 \mathrm{~m}$ to $380 \mathrm{~m}$ a.s.l. The terrain map was just a background image, which illustrated 2 meters interval contours. The forest type map particularly in planted forest areas consisted of Japanese cedar (Cryptomeria japonica), Japanese cypress (Chamaecyparis obtusa) and other species in the area ratio of Japanese cedar 6: Japanese cypress 3: others 1 . The road network in the forest road map extended over a distance of $23 \mathrm{~km}(11 \mathrm{~m} / \mathrm{ha})$ with 51 logging yards. The inventory data were corresponding to subcompartment attributes such as stand age, tree species, etc.

By use of these data, thematic maps of stand age over rotation age, site quality, accessibility and slope stability were created and combined after conversion into a common scale of standard scores. In this study, the following Z-score was used as a standard score:

$$
Z=\frac{10(x-\mu)}{\sigma}+50
$$

where $x$ : indicators of stand age [years old], a site index [m], a distance from a yard [m] and a safety factor describing thematic maps, $\mu$ : means of indicators and $\sigma$ : standard deviations of indicators. Then, stands suitable for clearcutting and reforestation were selected considering yarding feasibility.

Making Thematic Maps

Planted Stand Age Map over Rotation Age

A stand age map was useful to judge an amount of yield volume and priority of harvesting order. Thus, older stand age leaded to higher suitability for clearcutting. First, planted stands whose age was over the rotation age of 80 years old were extracted. Then, their stand ages were converted into standard scores.

The following several thematic maps were finally all expressed by standard scores. In every map, a higher standard score meant higher suitability for clearcutting and/ or reforestation.

\section{Site Quality Map of Japanese Cedar}

A site quality map was useful to judge an amount of yield volume. Thus, higher site quality leaded to higher suitability for clearcutting. The site indices of Japanese cedar, as the dominant tree heights at the age of 40 years old, in the Chiba forest were estimated by the following function (Hiroshima and Nakajima, 2009) using the terrain characteristics derived from the DEM (Chen and Abe, 1999; Mitsuda et al., 2001, 2007; Munajati et al., 2009) for each point on the 10-m grid of the dominant Japanese cedar trees:

[Site index $]=0.0167[$ Shaded relief $]+0.0144$ [Flow accumulation] -0.0932 [Curvature] +0.141 [Distance from ridge $]+0.0748$ [Slope angle] +11.5

Then the estimated site indices were converted into standard scores. In this study, a site index was calculated only for Japanese cedar to judge site quality all over the Chiba forest area because most sub-compartments in the Chiba forest had Japanese cedars planted in the large parts of the middle to bottom slopes with mixtures of Japanese cypresses planted only along the small parts of ridges.

\section{Accessibility Map}

An Accessibility map was useful to judge productivity and profitability of harvesting works. As mentioned above, a cable logging system had been applied in the Chiba Forest, so that buffers were created from the 51 logging yard points where dram machines were assumed to be set. In this case, shorter distance from a yard leaded to higher suitability for clearcutting. Finally, the distances from yards were converted into standard scores.

\section{Slope Stability Map}

A slope stability map was useful to judge the possibility that reforested stands successfully got matured. Thus, higher 
slope stability leaded to higher suitability for reforestation. First, the safety factor of a slope was calculated for each 10-m grid using the stability analysis function of an infinite slope (Mizuta and Seo, 2001; Okimura and Ichikawa, 1985; Shima and Ebisu, 2008) with the parameter values mainly observed in the Chiba Forest:

$$
S F=\frac{c+\left\{\left(\gamma_{\text {sat }}-\gamma_{w}\right) h+\gamma_{t}(H-h)\right\} \cos ^{2} \alpha \tan \beta}{\left\{\gamma_{\text {sat }} h+\gamma_{t}(H-h)\right\} \sin \alpha \cos \alpha}
$$

where $S F$ : a safety factor, $c=1.50$ (Shuin, 1997): cohesion $\left[\mathrm{tm}^{-2}\right], \alpha$ : a slope angle of each 10-m grid derived from the DEM [degree], $\beta=41.8$ (Sugisaki, 2002): an internal friction angle [degree], $\gamma_{\text {sat }}=1.90$ (Mizuta and Seo, 2001): saturated soil density $\left[\mathrm{tm}^{-3}\right], \gamma_{w}=1.00$ : water body density $\left[\mathrm{tm}^{-3}\right], \gamma_{t}=1.70$ (Mizuta and Seo, 2001): wet soil density [ $\left.\mathrm{tm}^{-3}\right], H$ : surface soil depth of each 10-m grid derived from the DEM (Sakai et al., 2011; Shiraki, 1993) [m], $h$ : groundwater level of each 10-m grid derived from the DEM (Goshima et al., 2008) [m]. Then, the estimated safety factors were converted into standard scores.

\section{Combination of 4 Thematic Maps}

The 4 thematic maps were combined with equal weight, i.e. simply averaging 4 standard scores in each 10-m grid. These combined scores also had the mean of 50 and the standard deviation of 10 in their distribution, and a higher score leaded to higher suitability for clearcutting and reforestation considering all 4 aspects of stand age, site quality, accessibility and slope stability. Then, the mean combined scores for sub-compartments were calculated by averaging the combined scores for $10-\mathrm{m}$ grids included in each sub-compartment. Finally, the sub-compartments with their mean combined scores over 50 and their areas over 3 ha were selected as the candidate sites for clearcutting and reforestation. Note that the threshold values of 50 and 3 ha were decided arbitrarily: The former was simply the mean of combined scores easily understood by interest parties as a selection standard in decision making scenes and the latter was based on the lower limit of harvesting sub-compartment size in the Chiba forest considering the efficiencies of following reforestation and tending works.

\section{Check on Yarding Feasibility}

Availability of cable logging was examined for the candidate sub-compartments. First, neighboring logging yards to the candidate sub-compartments were selected. Second, a visibility map from each logging yard was created. Third, yarding feasibility was examined by the help of the visibility and terrain map: In visible area from the neighboring yard, the straight line, assuming a sky cable line for logging, was set between the terrain peaks where one peak was set around the harvesting stand and the other peak was set around the yard, and then the vertical cross sectional map of a terrain along the line was checked to see if there was any obstacle between the peaks.

\section{RESULTS}

Planted Stand Age Map over Rotation Age

148 sub-compartments were extracted as the planted stands whose age were over the rotation age of 80 years old, which consisted of 39,238 grids in the raster data with the mean of 98 years old and the standard deviation of 11 years old. The standard score expressions were shown in Fig. 1-a by a map and in Fig. 2-a by a histogram. Note that each dot in the map and each frequency in the histogram represented a 10-m grid derived from the DEM. In addition, the standard scores were rounded off to integer values.

\section{Site Quality Map of Japanese Cedar}

Using Eq. 2, the site indices of the above 148 subcompartments were calculated for the corresponding grids with the mean of 16.4 meters and the standard deviation of 5.5 meters. The standard score expressions were shown in Fig. 1-b by a map and in Fig. 2-b by a histogram.

\section{Accessibility Map}

The distances from logging yards, i.e. accessibilities, of the above 148 sub-compartments were calculated for the corresponding grids with the mean of 1,052 meters and the standard deviation of 432 meters. The standard score expressions were shown in Fig. 1-c by a map and in Fig. 2-c by a histogram.

\section{Slope Stability Map}

The safety factors of the above 148 sub-compartments were calculated by Eq. 3 for the corresponding grids with the mean of 4.3 and the standard deviation of 3.1. The standard score expressions were shown in Fig. 1-d by a map and in Fig. 2-d by a histogram.

\section{Combination of 4 Thematic Maps and Yarding Feasibility Check}

The combined map and its histogram were shown in Figs. 1-e and 2-e. There were 18 candidate sub-compartments (Table 1 and bold black and blue polygons in Fig. 1-e) with their mean combined scores over 50 and their area over 3 ha, in which 5 sub-compartments were useless for harvesting because they contained experimental plots, educational facilities, etc. Then, the yarding feasibilities of the rest 13 subcompartments were checked (Fig. 3 for the example of the sub-compartment 44C11) and 6 sub-compartments (bold blue polygons in Fig. 1-e) of 45C10, 11C1, 44C11, 23C3, 43C 3 and 19C6 passed consequently. Among them, 4 subcompartments of $23 \mathrm{C} 3$ in the first year, $44 \mathrm{C} 11$ divided into 2 parts in the second and third year, $11 \mathrm{Cl}$ in the fourth year and $45 \mathrm{C} 10$ in the fifth year were selected as clearcutting and following reforestation stands in the new forest management plan. These 4 sub-compartments were selected in order of the mean combined score and the other stuff such as 
a)

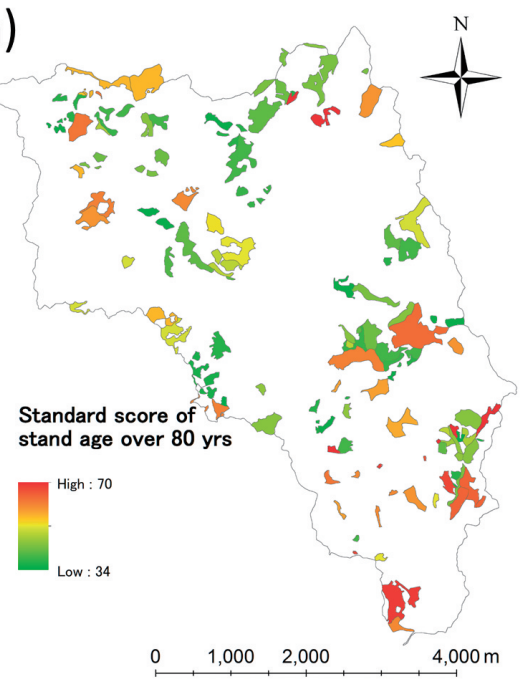

c)

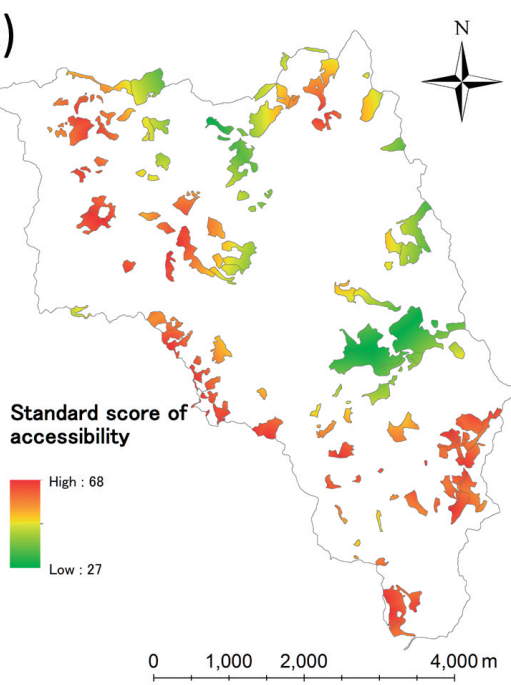

b)

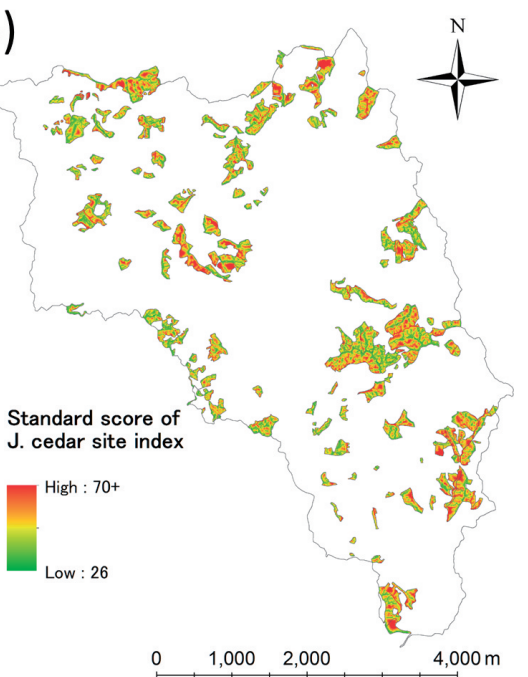

d)

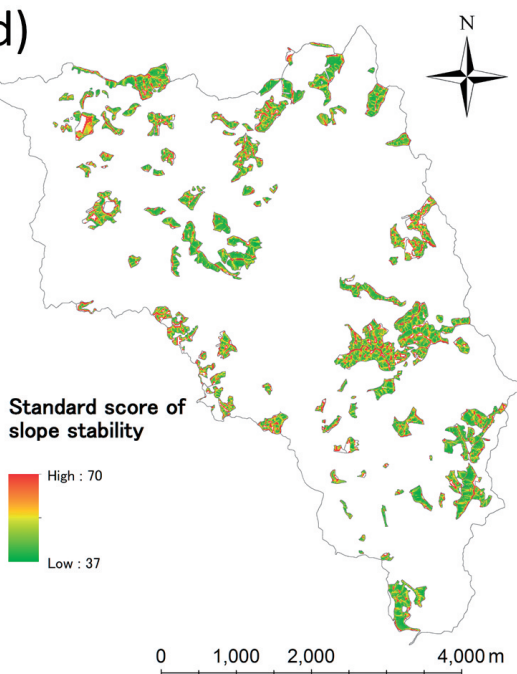

e)

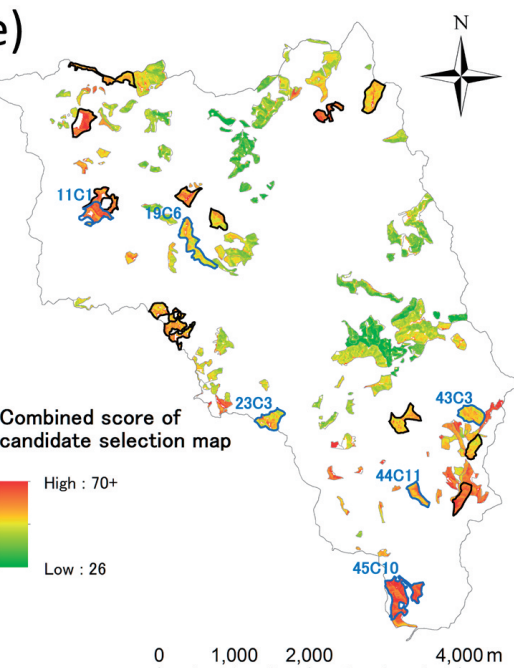

Fig. 1 Thematic maps expressed by a deviation value: a) stand age over the rotation age of 80 years old, b) site index of Japanese cedar, c) accessibility, d) slope stability and e) their combination with equal weight. The bold black and blue polygons represent 18 candidate sub-compartments with their mean combined scores over 50 and their area over 3 ha. Particularly the blue polygons represent finally selected 6 subcompartments which passed yarding feasibility checks. 

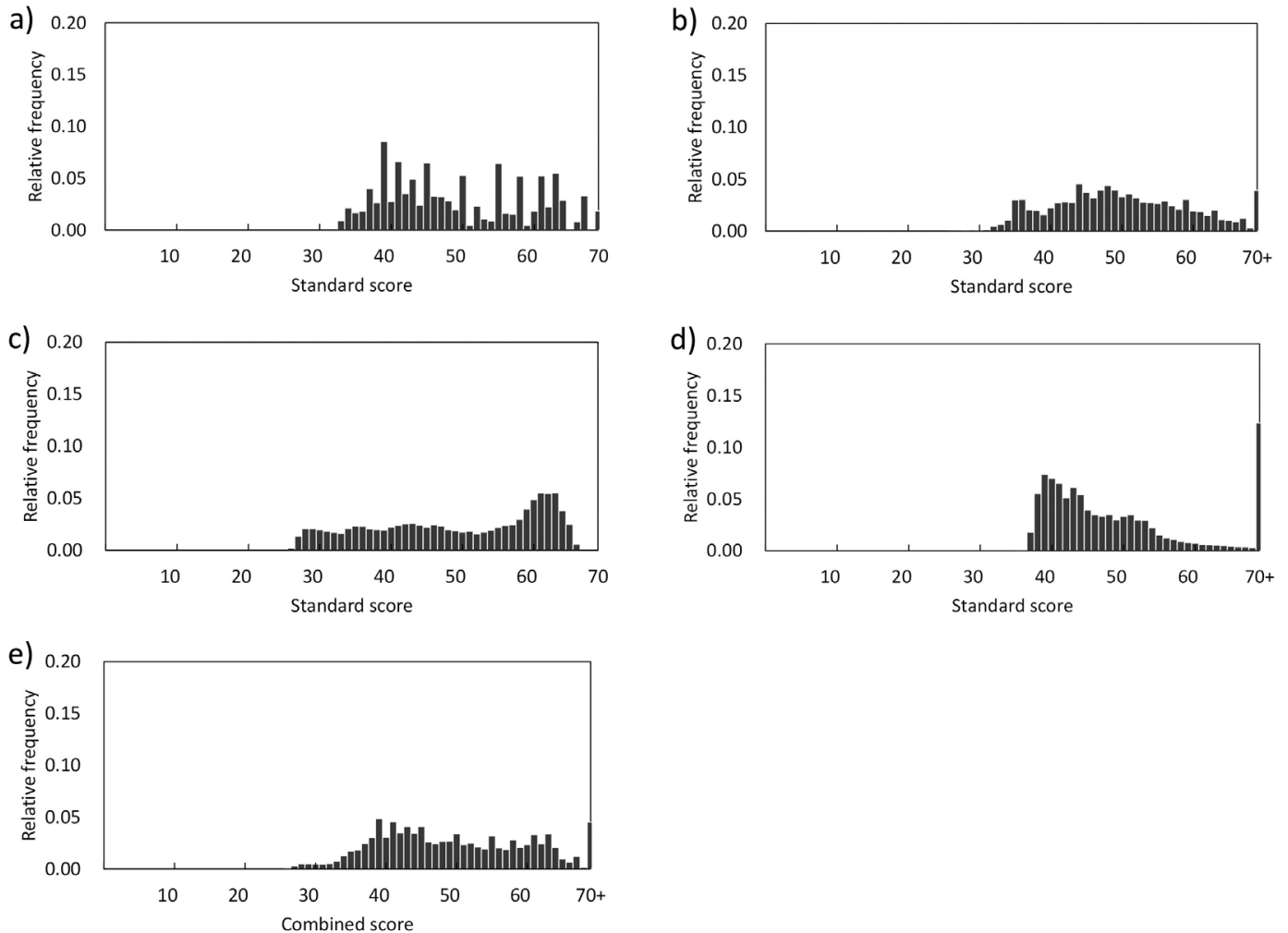

Fig. 2 Histograms of standard scores and a combined score: a) stand age over the rotation age of 80 years old, b) site index of Japanese cedar, c) accessibility, d) slope stability and e) their combination with equal weight.

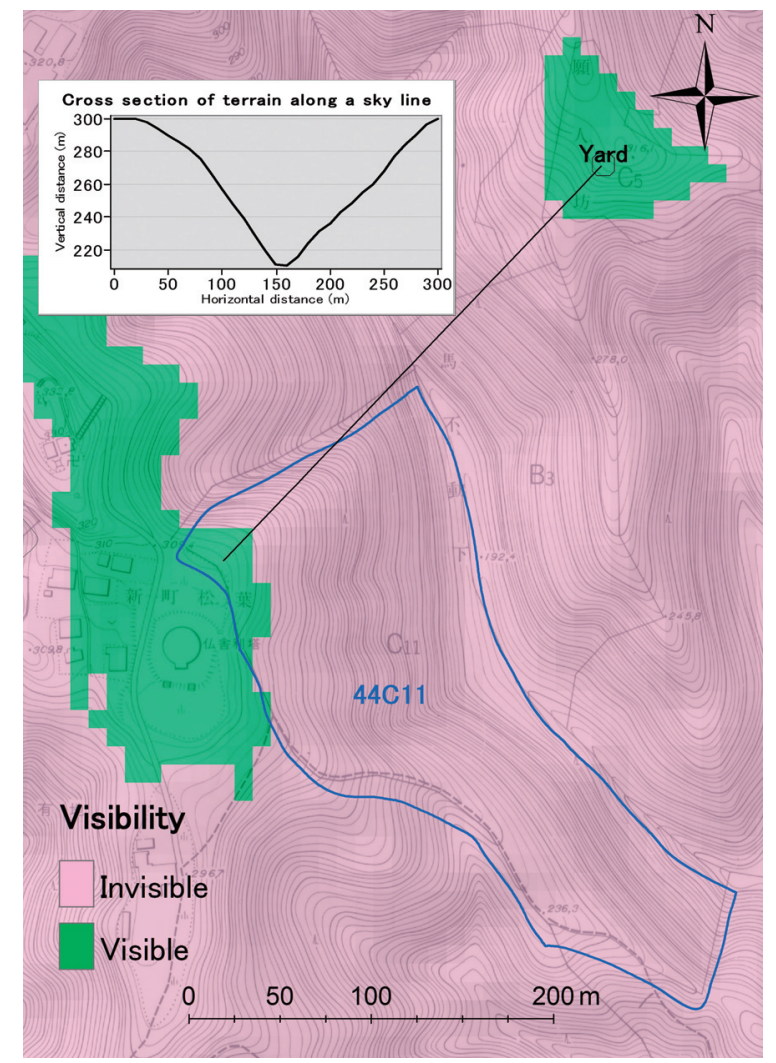

Fig. 3 Yarding feasibility check in the case of candidate sub-compartment 44C11. The black line represents a sky cable line for logging set between the two peaks in the green visible area from the neighboring yard to see if there was any obstacle in the vertical cross sectional map of a terrain along the line as shown in the lefttop graph. 
Table 1 Combined scores and areas of 18 candidate subcompartments.

\begin{tabular}{cccc}
\hline $\begin{array}{c}\text { Sub- } \\
\text { compartment }\end{array}$ & $\begin{array}{c}\text { Mean (Min, Max) } \\
\text { combined score }\end{array}$ & $\begin{array}{c}\text { Area } \\
\text { (ha) }\end{array}$ & Remarks \\
\hline $45 \mathrm{C} 10$ & $57(52,67)$ & 12.7 & \\
$46 \mathrm{C} 8$ & $56(52,66)$ & 4.9 & Thinned recently \\
$2 \mathrm{C} 5 \mathrm{a}$ & $56(51,62)$ & 5.1 & Incl. exp. plots \\
$27 \mathrm{C} 4$ & $56(53,65)$ & 3.8 & Incl. exp. plots \\
$11 \mathrm{C} 1$ & $55(50,65)$ & 5.5 & \\
$10 \mathrm{C} 1$ & $54(49,65)$ & 4.1 & Incl. facilities \\
$15 \mathrm{C} 5$ & $54(49,63)$ & 3.9 & \\
$44 \mathrm{C} 11$ & $53(48,64)$ & 3.7 & \\
$21 \mathrm{C}$ & $52(47,59)$ & 5.9 & Incl. exp. plots \\
$20 \mathrm{C} 1$ & $52(47,61)$ & 4.3 & \\
$6 \mathrm{C} 1$ & $52(47,56)$ & 5.2 & \\
$39 \mathrm{C} 3$ & $51(47,61)$ & 6.2 & \\
$28 \mathrm{C} 1$ & $51(47,61)$ & 7.2 & \\
$46 \mathrm{C} 4$ & $51(46,62)$ & 3.6 & \\
$23 \mathrm{C} 3$ & $51(46,61)$ & 5.8 & \\
$43 \mathrm{C} 3$ & $51(47,59)$ & 6.0 & \\
18C6 & $51(46,60)$ & 4.2 & \\
$19 \mathrm{C} 6$ & $50(46,60)$ & 9.0 & \\
\hline
\end{tabular}

harvesting year, a division of a harvesting sub-compartment, etc. depended on the contracts with harvesting companies.

Distributions of Scores in 4 Thematic Maps and Combined Map

In Fig. 2, the distributions of standard scores in 4 thematic maps were different respectively. Note that all these thematic maps extracted only the grids in planted stands over 80 years old. The score distribution of stand age (Fig. 2-a) had roughly two peaks around 43 and 64, and had several spikes that reflected the concentrations of stand ages on several particular ages. The score distributions of a site index, accessibility and slope stability had roughly all single peaks but their skewness were different. The distribution of a site index (Fig. 2-b) did not skewed, which showed old planted stands of the Chiba Forest had generally medium site qualities of Japanese cedar; high quality sites were not many but low quality sites were also not many. The distribution of accessibility (Fig. 2-c) was left-skewed, which showed old planted stands had relatively good accessibility from logging yards. The distribution of slope stability (Fig. 2-d) was right-skewed, which showed old planted stands tended to locate in the places relatively vulnerable to shallow land collapse.

In Figs. 2-a, 2-b, 2-c and 2-d, the percentages of grids with standard scores over 55 were $40 \%, 32 \%, 44 \%$ and $25 \%$ respectively, and these grids were shown as orange to red colors in the maps of Figs 1-a, 1-b, 1-c and 1-d. If the distribution was left-skewed then orange to red parts increased in the map and vice versa.

In Figs. 2-b and 2-d, there were grids with standard scores over 70 . The standard scores of 70 were equivalent to the 96 percentile value of 28.3 meters in the case of a site index and 88 percentile value of 10.9 in the case of a safety factor. Particularly in the case of a site index, some grids in the $70+$ class had meaninglessly large values such as over 50 meters as a result of extrapolation by Eq. 2 though they had little influences on the combined results considering their few frequencies.

The score distribution of the combined map (Fig. 2-e) had roughly two peaks around 44 and 63 mainly as a result of averaging two peaks (Fig. 2-a), left-skewed (Fig. 2-c) and right -skewed (Fig. 2-d) distributions. The percentages of grids with combined scores over 50 , which was the threshold of selecting candidate sub-compartments, was $48 \%$, so that almost half of the grids deserved suitable sites for clearcutting and reforestation in the old planted stands. In this case, the threshold of 50 , simply the mean of combined scores, had the percentile of $52 \%$ which eventually resulted in 18 candidate sub-compartments over 3 ha enough for harvesting in coming 5 years, but a threshold itself was subject to change owing to score distributions: If candidate sub-compartments were not enough like in case of a rightskewed distribution, a threshold should be lowered. For reference, the thresholds of combined score of 45 and subcompartment size of 1ha would result in 73 candidate subcompartments in case of this study.

\section{Details of Selected Sub-compartments}

The details of finally selected 4 sub-compartments were shown in Table 2. The table contained mean standard scores, corresponding mean original values of 4 indicators describing thematic maps and resultant mean combined scores. All 4 sub-compartments had mean combined scores over 50 similarly, but their combinations of mean standard scores for the indicators differed: Most standard scores were over 50 but the sub-compartments $45 \mathrm{C} 10,44 \mathrm{C} 11$ and $23 \mathrm{C} 3$ partly included the scores under 50 . The standard scores of distance from yard tended to be high in all 4 sub-compartments because the percentage of grids with standard scores over 60 was highest among 4 indicators as shown in Fig. 2, which contributed to heighten the combined scores consequently.

In terms of the original values of indicators in 4 subcompartments, the stand age ranged from 92 years old, no problem to harvest, to 117 years old, the third oldest stand in harvestable planted forests. The site index ranged from 15 meters, classified to the third grade of site class II among Ia, I, II and III of Japanese cedar in the yield table of the Chiba forest (Shiraishi, 1986), to 18 meters, the second grade of site class I. The distance from yard ranged from 301 meters, barely profitable considering stumpage values and cable logging costs in spite of a relatively long logging distance for recent clearcutting site, to 80 meters, so near that timbers around yards would be directly collectable without a cable. The safety factor ranged from 2.8, almost no problem for slope stability, to 4.8 , enough stable for following reforestation and tending works.

On the whole, though some indicators were under the standard score of 50 in spite of the resultant combined scores over 50 , the original values themselves were in the allowable ranges for clearcutting, logging and reforestation. 
Table 2 Mean standard scores, original values and combined scores of finally selected 4 sub-compartments.

\begin{tabular}{cccccccccc}
\hline \multirow{2}{*}{$\begin{array}{c}\text { Sub- } \\
\text { compartment }\end{array}$} & $\begin{array}{c}\text { Standard } \\
\text { score }\end{array}$ & $\begin{array}{c}\text { Original } \\
\text { value } \\
\text { (yrs. old) }\end{array}$ & $\begin{array}{c}\text { Standard } \\
\text { score }\end{array}$ & $\begin{array}{c}\text { Original } \\
\text { value } \\
(\mathrm{m})\end{array}$ & $\begin{array}{c}\text { Standard } \\
\text { score }\end{array}$ & $\begin{array}{c}\text { Original } \\
\text { value } \\
(\mathrm{m})\end{array}$ & $\begin{array}{c}\text { Standard } \\
\text { score }\end{array}$ & $\begin{array}{c}\text { Original } \\
\text { value }\end{array}$ & $\begin{array}{c}\text { Combined } \\
\text { score }\end{array}$ \\
\hline $45 \mathrm{C} 10$ & 67 & 117 & 52 & 18 & 62 & 153 & 47 & 3.3 & 57 \\
$11 \mathrm{Cl} 1$ & 58 & 107 & 50 & 16 & 64 & 80 & 50 & 4.4 & 55 \\
$44 \mathrm{C} 11$ & 58 & 107 & 51 & 17 & 58 & 301 & 45 & 2.8 & 53 \\
$23 \mathrm{C} 3$ & 44 & 92 & 47 & 15 & 63 & 116 & 52 & 4.8 & 51 \\
\hline
\end{tabular}

\section{DISCUSSION}

\section{Use of a Standard Score in Combining Thematic Maps}

It was convenient to use a standard score as a unit of a thematic map in combining several maps originally expressed by different units. The unit of a standard score was non-dimensional, so once the units of thematic maps such as meter, degree, etc. were converted into a common scale of a standard score, any kind of thematic maps can be combined to enable overall evaluation through the maps.

On the other hand, a standard score should be handled with care particularly in relative comparison among different indicators, areas, etc. In case of this study, the standard score distributions were different among 4 indicators as shown in Fig. 2, so the same standard score of each indicator were not related with the same relative ranking because of different percentiles. For instance, the same standard score of 60 for 4 indicators corresponded to the different percentiles of $76 \%$, $81 \%, 68 \%$ and $77 \%$ as mentioned above, so the indicator of site index held the highest relative rank with the largest $81 \%$ percentile. In addition, even if all indicators had the same standard score distributions such as a normal distribution, the same standard scores did not necessarily have the same extent of suitability for harvesting. For the hypothetical instance, assuming both a safety factor and distance from yard belonged to normal distributions and the standard scores of 55 with the same percentile of $69 \%$ corresponded to the original values of 0.9 and 300 meters respectively, the standard score of 55 for distance from yard was more suitable for harvesting. The reason was that the safety factor under 1.0 meant instable state of slopes unsuitable for harvesting and following reforestation while yarding distance under 500 meters allowed cable logging somehow. Moreover, if one indicator was applied to several areas with different conditions, this case might lead to the same standard scores with different extent of suitability even in the same indicator. For the hypothetical instance, assuming the standard scores of a site index were calculated for compartments $\mathrm{A}$ and $\mathrm{B}$ in different terrain conditions, the same standard scores of 60 for both $\mathrm{A}$ and $\mathrm{B}$ would correspond to different original values of such as 20 meters for $A$ and 15 meters for B according to the different standard score distributions, where the former 20 meters classified in the site class I and the latter 15 meters in II resulted in the different suitability for harvesting.

In spite of the above matters with care, it was still convenient to use a standard score in combining several maps considering the following advantages. The mean of 50 and standard deviation (SD) of 10 , in case of a Z-score, were common, which leaded to the fact in common that the standard score of 60 represented a mean $+1 \mathrm{SD}, 70$ represented a mean $+2 \mathrm{SD}$ and so on. It was certain, therefore, for any indicator (here, though the difference of indicator was discussed as an example, the following facts were common in discussing the difference of area, time, etc.) that a higher standard score simply held a better rank in a score distribution, so the increase in selection thresholds of combined scores from 50,55, 60 and so on enabled the selections of totally better-balanced sub-compartments considering standard scores of all indicators including various cases such as all indicators got higher ranks, some got much higher ranks but some got a little lower ranks, etc. as shown in Table 2. Thus, when we needed to select subcompartments almost better than an average, it could be settled by selecting the sub-compartments with combined scores over 50 after converting original indicator values into standard scores on condition that original indicator values of selected sub-compartments were all in the allowable ranges for clearcutting, logging and reforestation. The subcompartments with combined scores over 50 could be regarded as well-balanced taking all indicators into account.

In the end, a standard score should be handled with care in relative comparison among different indicators, areas, etc. However, if the meaning of a standard score and corresponding relative ranking were understood correctly, the use of a standard score was convenient for decision making such as the selection of sub-compartments almost better than an average.

\section{CONCLUTION}

In this study, suitable sites for clearcutting and reforestation were found by combining GIS thematic maps of stand age, site quality, accessibility and slope stability expressed by standard scores in the case of the University of Tokyo Chiba Forest. Particularly a standard score was useful to set several thematic maps into a common scale when they were combined, which enabled the selection of well-balanced sub-compartments in all aspects of thematic maps as long as the meaning of a standard score and corresponding relative ranking were understood and handled correctly. The suggested method in this study is flexible and can contribute to a wider use of GIS in the field of forest planning. 


\section{ACKNOWLEDGEMENTS}

This study was supported by the Grant-in-Aid for Scientific Research (C) 25450207. The author appreciates the valuable comments by anonymous reviewers to improve this study.

\section{LITERATURE CITED}

Chen, J. and Abe, N. (1999) Site classification for Sugi plantations using GIS. J. For. Plann. 5: 1-8

Goshima, M., Shuin, Y., Tasaka, T., Aruga, K., Matsue, K. and Naito, K. (2008) Relation between shallow landslide on hill slopes and distribution of soil depth, soil structure in Funyu forest, Utsunomiya University. Bull. Utsunomiya Univ. For. 44: $15-32$.

Hiroshima, T. and Nakajima, T. (2009) Extracting old-growth planted stands suitable for clear cutting and reforestation using GIS. Kanto J. For. Res. 60: 43-46.

Kato, S. (1967) Studies on the forest road system: Preliminary report on the road density. Bull. Tokyo Univ. For. 63: 215-233.

Kawata, S. and Matsumura, N. (2006) Forest management system conducted by forest zoning procedure and official support for private forests: Applicability of GIS for Sugi plantation forests in Misugi Village, Mie Prefecture. Jpn. J. For. Plann. 40: 57-63.

Lee, J. S. and Minowa, M. (2002) Strategic forest harvest planning using GIS and LP. Trans. Mtg. Kanto Br. Jpn. For. Soc. 54: 55-56.

Mitsuda. Y., Ito, S. and Sakamoto, S. (2007) Predicting the site index of sugi plantations from GIS-derived environmental factors in Miyazaki Prefecture. J. For. Res. 12: 177-186.

Mitsuda, Y., Yoshida, S. and Imada, M. (2001) Use of GIS-based environmental factors in predicting site indices in Japanese Larch plantations in Hokkaido. J. For. Res. 6: 87-93.

Mizuta, T. and Seo, K. (2001) Prediction of slope failure potential induced by heavy rain using digital elevation model: A case study for Nagasaki city. J. Jpn. Soc. Nat. Disaster Sci. 19: 477-491.

Moriya, T., Tatsuhara, S., Nakajima, T., Tanaka, T. and Tsuyuki, S. (2013) A method to determine thinning priorities using a geographic information system and Analytic Hierarchy Process. Jpn. J. For. Plann. 46: 57-66.

Munajati, S. L., Abe, N. and Tsukahara, M. (2009) Predicting site indices of Japanese cedar plantation in Niigata prefecture using environmental factors. J. For. Plann. 15: 45-51.

Nakajima, T., Hirata, Y., Hiroshima, T., Furuya, N., Tatsuhara, S., Tsuyuki, S. and Shiraishi, N. (2011) A growth prediction system for local stand volume derived from LiDAR data. GISci. Remote Sens. 48: 394-415.

Nakaya, A., Nagashima, K. and Tanaka, K. (2014) Relationship between the site condition and the distribution of Ilex pedunculosa in Kyoto Takaragaike Park. Jpn. J. For. Plann. 48: $1-12$.

Okimura, T. and Ichikawa, R. (1985) A delineation method for probable mountain slope failures by a digital land form model. J. Jpn. Soc. Civ. Eng. 358: 69-75.

Sakai, Y., Kinoshita, A., Nakata, S., Matsuda, M. and Ogawa, K. (2011) Research on surface depth estimation using airborne laser and field survey. Trans. Mtg. Jpn. Ero. Contr. Eng. 60: 404-405.

Sano, M., Inose, M., Ishibashi, S. and Kogi, K. (1994) Analysis of the relation between terrain and forest types in natural forest using GIS. Trans. Jpn. For. Soc. 105: 135-136.

Sano, M., Miyamoto, A., Furuya, N. and Kogi, K. (2009) Using landscape metrics and topographic analysis to examine forest management in a mixed forest, Hokkaido, Japan: Guidelines for management interventions and evaluation of cover changes. For. Ecol. Manag. 257: 1208-1218.

Sano, M. and Sakamoto, T. (1998) Examination of making watershed management plan considering various viewpoints for land use. J. Jpn. For. Soc. 80: 120-128.

Sano, M., Sakanmoto, T. and Tsuchiya, T. (1996) Making a watershed management plan using the geographic information system. J. Jpn. For. Soc. 78: 1-9.

Shima, S. and Ebisu, T. (2008) Study on landslide factor and stability analysis of slope failure. Bull. Hiroshima Inst. Tech. Res. 42: 91-98.

Shiraishi, N (1986) Study on the growth prediction of evenaged stands. Bull. Tokyo Univ. For. 75: 199-256.

Shiraki, K. (1993) Evaluation of runoff characteristics in the Fukuroyamasawa experimental two watersheds in the University of Tokyo Chiba Forest (tentative translation by author). Graduation thesis of the Univ. Tokyo, 31pp.

Shuin, Y. (1997) Experimental research on the effect evaluation of soil moisture fluctuation on soil reinforcement by tree root (tentative translation by author). Doctoral thesis of the Univ. Tokyo, 115pp.

Sugisaki, T. (2002) Stability analysis of slope failure monitoring site considering various intervening factors (tentative translation by author). Master thesis of the Univ. Tokyo, 72pp.

Tatsuhara, S. (2008) Zoning sugi (Cryptomeria japonica) plantations into silvicultural systems. 29-36, In Takahashi, N., Feng, F. L. and Nobori, Y. (eds.) Toward the Establishment of the Multi-purpose and Long-term Forest Management Plans. Japan Society of Forest Planning Press, Utsunomiya, 148pp.

Tatsuhara, S. and Dobashi, T. (2006) Classifying plantation forests in a snowy region according to cutting age using GIS: A case study of private forests in Sanpoku Town, Niigata Prefecture. J. For. Plann. 12: 11-22.

The University of Tokyo Chiba Forest, Graduate School of Agricultural and Life Sciences, The University of Tokyo (2012) The 13th education and research plan of the University of Tokyo Chiba Forest (2011-2020). Misc. Inform. Univ. of Tokyo For. 51: 27-66.

Toyama, K., Hiroshima, T., Murakawa, I., Tsukagoshi, T., Oishi, S. and Karukome, T. (2013) Search of "Forest Management Plan" which satisfies operational constraints in the University of Tokyo Chiba Forest. Kanto J. For. Res. 64(2): 1-4.

Toyama, K. and Tatsuhara, S. (2007) Stand and setting conditions required for efficient cable logging. Jpn. J. For. Plann. 41: 169-178. 
Toyama, K. and Tatsuhara, S. and Shiraishi, N. (2012) Simulation under diverse conditions for profitable thinning regime and clearcutting age in planted Cryptomeria japonica forest. J. Jpn. For. Soc. 94: 269-279.

Umezawa, T., Nagashima, K. and Tanaka, K. (2013) Create a guide map of forestry operation of Tango region in Kyoto Prefecture, Japan. Jpn. J. For. Plann. 47: 93-101.

Watanabe, S. and Tatsuhara, S. (2013) A long-term harvest scheduling model involving two types of rotation and variable labour requirements. J. For. Plann. 19: 17-26.

$\mathrm{Wu}$, S. and Minowa, M. (2004) A study of forest GIS construction and function assessment in Asahi forest. Trans. Mtg. Kanto Br. Jpn. For. Soc. 55: 81-82.

Yamada, Y. and Tatsuhara, S. (2012) Examination of maximum sustainable timber yield based on a profitability simulation. J. For. Plann. 18: 1-11.

Zheng, Y. and Nagumo, H. (1994) A forest activity classification method using a geographic information system. J. Jpn. For. Soc. 76: 522-530.

(Received 20 May 2015)

(Accepted 28 August 2015) 